\title{
Usinagem
}

\section{Efeito da usinagem na estrutura e propriedades mecânicas do aço superaustenítico ASTM A351 CN3MN}

\author{
Márcio Tadeu Gravalos \\ Sulzer Brasil S.A., Jundiaí, SP.E-mail:marcio.gravalos@sulzer.com \\ Marcelo Martins \\ Sulzer Brasil S.A., Jundiaí, SP.E-mail:marcelo.martins@sulzer.com
}

Anselmo Eduardo Diniz

Faculdade de Engenharia Mecânica da Unicamp, Campinas, SP. E-mail: anselmo@fem.unicamp.br

Paulo Roberto Mei

Faculdade de Engenharia Mecânica da Unicamp, Campinas, SP.E-mail: pmei@fem.unicamp.br

\begin{abstract}
Resumo
Os aços inoxidáveis superaustenítico são assim denominados, pois, além de apresentarem boa resistência à corrosão por pite, reúnem, também, excelentes propriedades mecânicas, o que os torna uma das opções para a fabricação de componentes utilizados pela indústria petrolífera. Entretanto o encruamento superficial, durante os processos de usinagem, pode alterar essas propriedades. Esse trabalho teve, por objetivo, investigar os efeitos da operação de torneamento, na superfície do aço superaustenítico ASTM A351 CN3MN. Amostras do aço fundido sofreram um desbaste por torneamento cilíndrico, com distintas velocidades de corte, utilizando-se de pastilhas de metal duro com geometrias variadas. A análise da microestrutura, na superfície fundida, foi realizada por microscopia óptica e a superfície encruada foi determinada através da microdureza. As propriedades mecânicas do aço foram determinadas por ensaio de tração. $\mathrm{O}$ desgaste nas pastilhas de corte foi observado em um MEV.
\end{abstract}

Palavras-chave: Aço inoxidável superaustenítico ASTM A351 CN3MN, usinagem, torneamento, encruamento.

\begin{abstract}
Super austenitic stainless steels are denominated as such because they present good resistance to pitting corrosion and, also, offer excellent mechanical properties, which makes them one of the options for the production of components used by the petroleum industry. However, the superficial foundry hardening during the machining processes can change these properties. This paper aimed at investigating the effects of the machining operation on the surface of the super austenitic steel ASTM A351 CN3MN. Samples of the casted steel suffered wear due to cylindrical machining, with different cutting speeds, using indexable carbide inserts of varied geometries. The analysis of the microstructure on the casting surface was accomplished by optical microscopy and the foundry hardened surface was determined by micro-hardness. The mechanical properties of the steel were determined by traction assay. The wear in the cutting inserts was accomplished in a $M E V$.
\end{abstract}

Keywords: Super austenitic stainless steel, machining, turning, work hardening. 


\section{Introdução}

Os aços inoxidáveis superaustenítico são assim denominados porque possuem uma elevada resistência à corrosão por pite, quando comparados com os aços inoxidáveis austeníticos convencionais. Além dessa característica, reúnem, também, excelentes propriedades mecânicas, tornando-os uma das opções na fabricação dos componentes utilizados em equipamentos da indústria petrolífera. A usinagem é um processo bastante utilizado na fabricação desses componentes.

Existem muitas publicações sobre a usinagem de aços inoxidáveis austeníticos convencionais, porém poucas sobre a usinagem dos aços inoxidáveis superausteníticos, o que motivou esse estudo.

Os aços inoxidáveis austeníticos convencionais apresentam uma grande dificuldade para serem usinados, devido à baixa condutividade térmica, ao alto coeficiente de atrito e ao alto coeficiente de dilatação térmica [03]. Durante o processo de usinagem desses aços, ocorre um aumento da temperatura na interface ferramenta-peça, que está relacionado com o aumento da velocidade de corte [12]; o atrito entre a ferramenta e o material gera elevadas forças de corte, que, também, contribuempara o aumento da temperatura. $\mathrm{O}$ aumento da temperatura e a baixa condutividade térmica, uma das características dos aços inoxidáveis austenítico, favorecem o aquecimento da superfície do material da peça para a formação do encruamento superficial [08].

O encruamento superficial significa um aumento considerável na dureza superficial, quando a estrutura do material é deformada durante o processo de usinagem [09]. O nitrogênio facilita o encruamento da fase austenítica [03] e, analisando-se a composição química de um aço superaustenítico, observa-se que a quantidade desse elemento é, aproximadamente, 4 vezes maior que num aço austenítico convencional. Para minimizar o encruamento, durante a usinagem, sugere-se a utilização de ferramentas com ângulo de saída positivo [07] e indica-se a utilização de ferramentas com cobertura de TiN (nitreto de titânio) para diminuir o atrito ferramenta-peça [11].
Esse trabalho, além de investigar o encruamento superficial, no aço superaustenítico ASTM A351 CN3MN, um dos efeitos causado pelo processo de usinagem, tem, também, como objetivo, o de investigar se o encruamento tem uma correlação com as diferentes condições de usinagem aplicadas. Os testes foram realizados através da operação de torneamento em desbaste com variações na velocidade de corte e no ângulo de saída da ferramenta. Além de abordar a caracterização das superfícies usinadas, através de ensaios de microdureza e de tração, foram abordadas, também, a caracterização do desgaste e as avarias nas ferramentas de corte utilizadas, através da análise por microscopia eletrônica de varredura. Diminuir o consumo de ferramentas, através do aumento da vida útil das mesmas, e aumentar a produtividade, através de maiores taxas de remoção de material por unidade de tempo, sem, contudo, causar efeitos indesejáveis nas propriedades do material usinado, representam fatores que reduzem os custos de fabricação dos componentes.

\section{Materiais e métodos}

Foram utilizadas amostras cilíndricas do aço inoxidável superaustenítico ASTM A351 CN3MN, com 95 mm de diâmetro e 200 mm de comprimento, fundidas pelo processo estático (Figura 1). Na Tabela 1, encontram-se a composição química do aço utilizado e seu PREN (Pitting Resistance Equivalent), valor que determina a resistência à corrosão por pite [01], calculado através da equação: $P R E N=C r \%+3,3 M o \%+16 N \%$

A zona da camada coquilhada proveniente do processo de fundição foi analisada através de um microscópio ótico Leitz Laborlux 12MES - Leica. A espessura da camada coquilhada foi caracterizada pela presença de vazios, como pode ser observado na Figura 2, apresentando uma espessura na faixa de 250 a $300 \mu \mathrm{m}$.

Com o objetivo de evitar a interferência dessa camada coquilhada, nas investigações das propriedades superficiais e na caracterização dos desgastes e avarias, nas superfícies das pastilhas de corte utilizadas, a camada coquilhada foi removida através de uma operação de usinagem prévia, onde foram retirados os primeiros $500 \mu \mathrm{m}$ de camada externa das amostras fundidas. Antes dos ensaios, as amostras ficaram cilíndricas com um diâmetro de 85mm, conforme podemos observar através da Figura 1.

Para realização da usinagem, foi utilizado um torno CNC Monarch 35TC1 de 30 kW de potência, rotação máxima de 2200 rpm e com diâmetro máximo de passagem de $440 \mathrm{~mm}$. Para investigar a influência do ângulo de saída ( $\gamma 0)$ no encruamento superficial, foram utilizadas duas diferentes ferramentas de corte, compostas de porta-ferramenta + inserto intercambiável:

- Um porta-ferramenta padrão ISO PCLNR 2525 M1, com ângulo de folga $(\alpha)$ de $6^{\circ}$ e ângulo de posição $(\chi r)$ de $95^{\circ}$.

- Dois tipos de insertos de metal duro intercambiáveis com diferentes valores dos ângulos de saída: $\mathrm{com}+10^{\circ} \mathrm{e}$ $+4^{\circ}$, padrão ISO CNMG 120412, com tripla cobertura composta de $\mathrm{Ti}(\mathrm{C}, \mathrm{N})$ $+\mathrm{Al}_{2} \mathrm{O}_{3}+\mathrm{TiN}$, comprimento da aresta de corte de $12 \mathrm{~mm}$, espessura de $4 \mathrm{~mm}$ e raio da ponta de 1,2 mm.

Como resultado, os ângulos de saída, em cada um dos conjuntos portaferramenta + inserto montado, eram, respectivamente, $+4^{\circ}$ (positivo) e $-3^{\circ}$ (negativo).

As amostras foram submetidas à mesma operação de usinagem: torneamento em desbaste. Os parâmetros de corte foram fixados com uma única profundidade de corte (ap) $=2,5 \mathrm{~mm}$ e um único avanço (f) = 0,25 mm/rotação. Para investigar o efeito da velocidade de corte $\left(V_{c}\right)$, no encruamento superficial, foram utilizados dois valores distintos de velocidade: $60 \mathrm{~m} / \mathrm{min}$ e $90 \mathrm{~m} / \mathrm{min}$.

O comprimento de corte, em cada passada, foi fixado em $140 \mathrm{~mm}$. Ao final de cada passe, os insertos eram retirados para avaliação e medição dos desgastes de flanco (VB) em um microscópio ótico. Como critério de fim de vida útil, foi adotado o valor de desgaste de 
Márcio Tadeu Gravalos et al.

flanco (VB) máximo de 0,8 mm ou avarias, como lascamentos, utilizando como padrão o que ocorresse primeiro durante os ensaios.

A Tabela 2 resume as três condições de usinagem aplicadas durante os ensaios.

A usinagem, em cada amostra, limitava-se a 6 passadas. Ao atingir o diâmetro de $55 \mathrm{~mm}$, as amostras eram retiradas do torno e um disco de espessura de $15 \mathrm{~mm}$ era extraído da cada amostra, para caracterização da superfície usinada. Para cada condição de usinagem, foram realizados ensaios de microdureza, nas secções transversais às superfícies usina- das, conforme Figura 3, em 2 amostras de cada. $O$ perfil de dureza possibilitou identificar a dimensão da camada endurecida durante a usinagem. Para obtenção do perfil de dureza, foram realizadas medidas em diferentes pontos, a partir da superfície usinada em direção ao centro. As medidas de dureza Vickers (HV) foram realizadas, utilizando-se uma carga de 100gf.

Com o objetivo de investigar se o encruamento superficial tem influência nos valores de propriedades mecânicas, obtidos através do ensaio de tração, foram confeccionados 2 corpos-de-prova de cada condição de usinagem, de acordo com padrão DIN 50125 forma C, os quais foram usinados nas mesmas condições estabelecidas na Tabela 2. Os ensaios foram realizados numa Máquina de Tração Universal marca Tinus Olsen Super L com capacidade para 30t e os valores encontrados foram comparados com os valores estabelecidos pela norma ASTMA351 grau CN3MN.

\section{Resultados e dicussões}

\subsection{Análise de dureza}

Nas regiões próximas da superfície usinada, todas as amostras atingiram

Tabela 1 - Valores da composição química (\% em peso) e do PREN.

\begin{tabular}{c|c|c|c|c|c|c|c|c|c|c|c}
\hline ELEMENTO & $\mathbf{S i}$ & $\mathbf{C}$ & Mo & $\mathbf{C r}$ & $\mathbf{S i}$ & $\mathbf{N i}$ & $\mathbf{P}$ & Mn & Cu & N & PREN \\
\hline AMOSTRA & 0,74 & 0,015 & 6,25 & 20,79 & 0,008 & 24,65 & 0,021 & 0,63 & 0,33 & 0,2 & 44,6 \\
\hline NORMA & 1 Máx. & 0,03 Máx. & 6,0 a 7,0 & 20 a 22 & 0,01 Máx. & 23,5 a 25,5 & 0,04 Máx. & 2 Máx. & 0,75 Máx. & 0,18 a 0,26 & $\geq 40$ \\
\hline
\end{tabular}

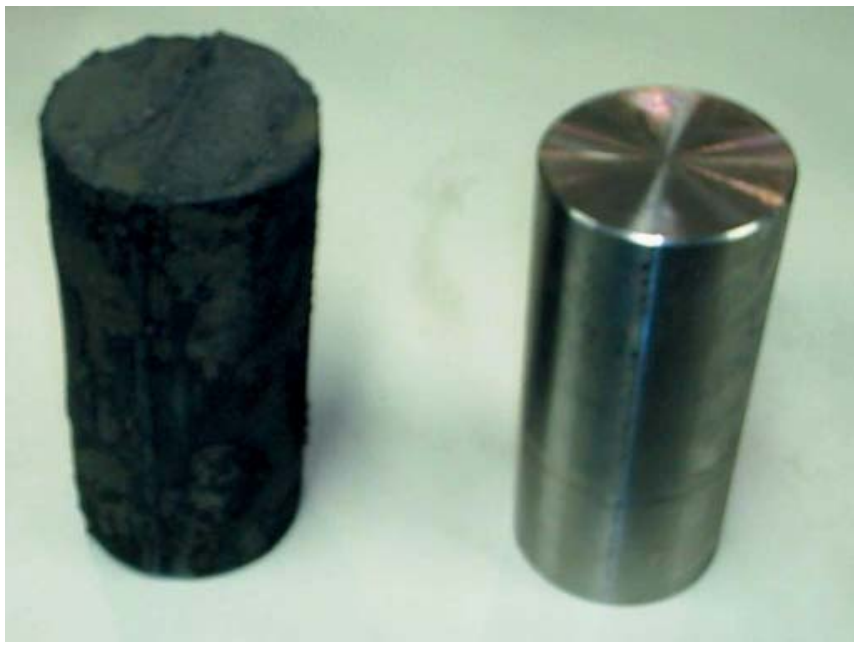

Figura 1 - Amostra fundida com e sem a camada coquilhada.

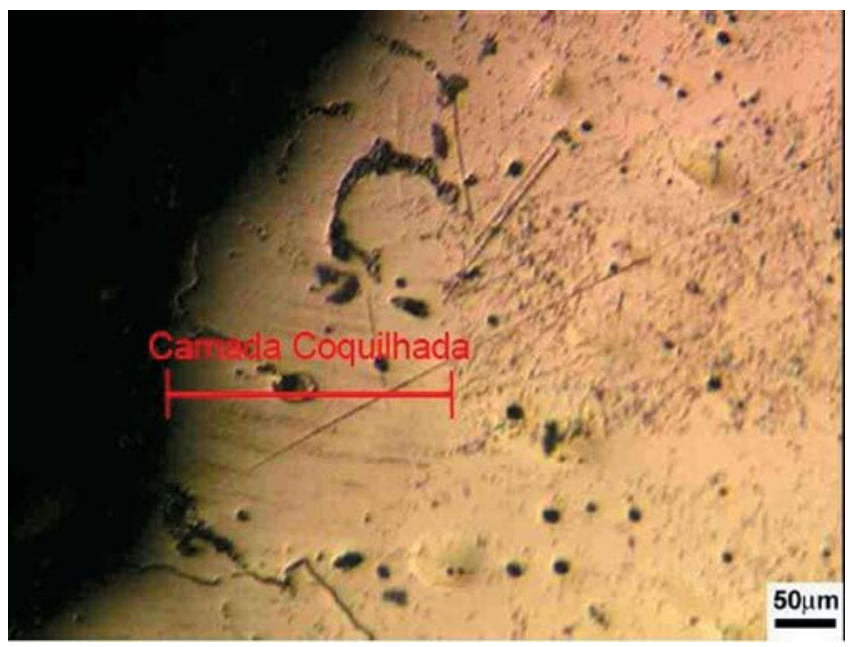

Figura 2 - Camada coquilhada.

Tabela 2 - Parâmetros empregados na usinagem das amostras.

\begin{tabular}{c|c|c|c|c|c}
\hline Código & $\begin{array}{c}\text { Ângulo de } \\
\text { saída }(\gamma \mathbf{0}) \\
\text { (graus) }\end{array}$ & $\begin{array}{c}\text { Velocidade de } \\
\text { corte (V) } \\
(\mathbf{m} / \mathbf{m i n})\end{array}$ & $\begin{array}{c}\text { Profundidade de } \\
\text { corte (ap) } \\
(\mathbf{m m})\end{array}$ & $\begin{array}{c}\text { Avanço (f) } \\
(\mathbf{m m} / \text { rotação) }\end{array}$ & $\begin{array}{c}\text { Comprimento de } \\
\text { corte (I) por } \\
\text { passada (mm) }\end{array}$ \\
\hline VC60 $\gamma_{0}+$ & 4 & 60 & 2,5 & 0,25 & 140 \\
\hline VC60 $\gamma_{0}$ & -2 & 60 & 2,5 & 0,25 & 140 \\
\hline VC90 $\gamma_{0}+$ & 4 & 90 & 2,5 & 0,25 & 140 \\
\hline
\end{tabular}


Efeito da usinagem na estrutura e propriedades mecânicas do aço superaustenítico ASTM A351 CN3MN

uma dureza média máxima da ordem de $350 \mathrm{HV}$, um valor 1,8 vezes maior, quando comparado com a dureza medida na região do substrato. Nota-se, também, que os valores de dureza estão decrescendo na medida em que se distancia da superfície, evidenciando que a usinagem provocou um encruamento nas amostras numa profundidade de até $350 \mu \mathrm{m}$, a partir da superfície usinada (Tabela 3 e Figura 4). A severidade do encruamento superficial pode ser estimada através da fórmula de Saoubi [10]:

$\Delta$ HVmáx./HVmáx. = $(H V m a x .-H V i n i c i a l)$ /HVmáx.

Utilizando-se os valores médios da Figura 5, obtém-se, então, uma severidade do encruamento de 0,45 .

\subsection{Análise das propriedades mecânicas}

A Tabela 4 compara os valores médio obtidos de propriedades mecânicas com os especificados pela norma ASTM A 351, grau CN3MN [01]. Os valores de Limite de Resistência (LR) e de Limite de Escoamento (LE) encontrados para todas as amostras estão de acordo com valores especificado pela norma, enquanto que os de Alongamento (Al) encontram-se abaixo do valor especificado.

\subsection{Análise dos desgastes e avarias nas ferramentas de corte}

\subsubsection{Aresta de corte}

Na Figura 5, pode-se notar que a ferramenta com ângulo de saída positivo apresentou um desgaste de flanco menor que a ferramenta com ângulo de saída negativo, utilizando-se a mesma velocidade de corte de $(60 \mathrm{~m} / \mathrm{min})$ e dentro do mesmo critério de fim de vida útil da aresta preestabelecido de VBmáx = 0,8 mm. Verificou-se, também, uma pequena redução do desgaste das

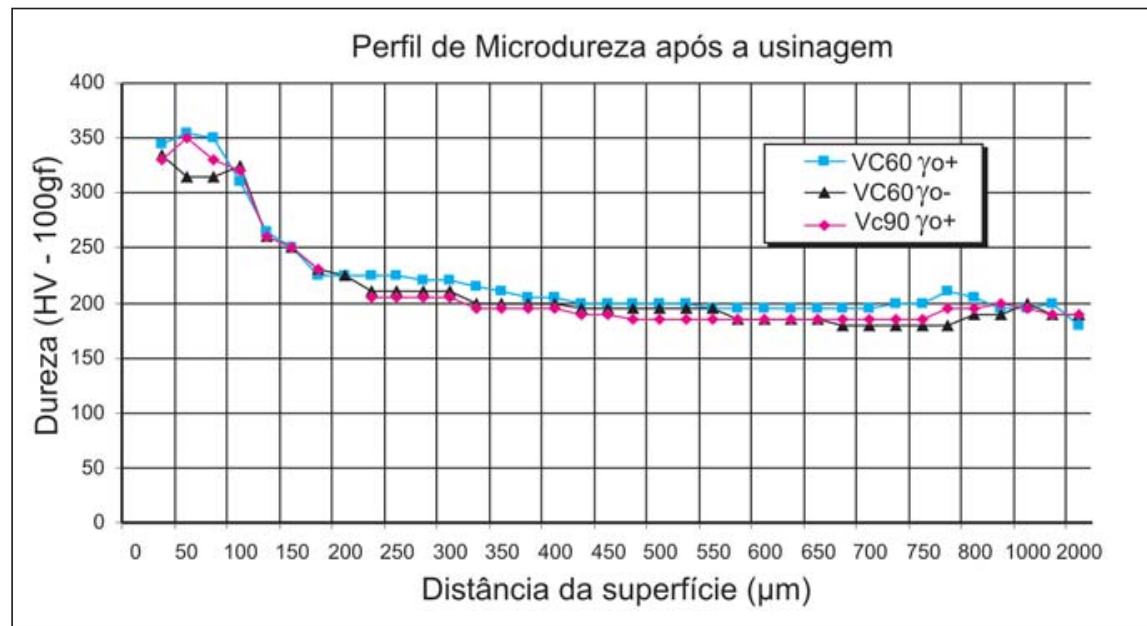

Figura 4 - Perfil de dureza das superfícies usinadas. ferramentas com ângulo de saída positivo, quando a velocidade de corte foi elevada de 60 para $90 \mathrm{~m} / \mathrm{min}$ (Figuras 5 e 6).

A ferramenta de corte com ângulo de saída positivo apresentou um resultado melhor quanto à vida útil. Por outro

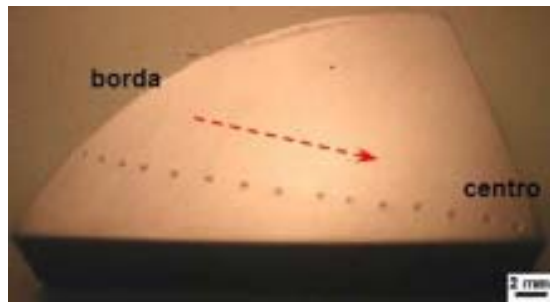

Figura 3 - Sentido de medição da dureza.

Tabela 3 - Valores da dureza média e do desvio-padrão em função da distância da superfície.

\begin{tabular}{|c|c|c|c|c|c|c|c|c|c|c|c|c|c|c|c|c|c|c|c|}
\hline Variável & Distância $(\mu \mathrm{m})$ & 25 & 50 & 75 & 100 & 125 & 150 & 175 & 200 & 225 & 250 & 275 & 300 & 325 & 350 & 375 & 400 & 425 & 450 \\
\hline \multirow{2}{*}{ VC60 ro+ } & Dure & 45 & 55 & 350 & 310 & 265 & 250 & 225 & 225 & 225 & 225 & 220 & 220 & 215 & 210 & 205 & 05 & 200 & 200 \\
\hline & Desv & 0,6 & 3,5 & 7,1 & 10,6 & 7,1 & 24,7 & 10,6 & 17,7 & 21,2 & 19,8 & 17,7 & 17,7 & 16,3 & 7,1 & 3,5 & 3,5 & 0,0 & 0,0 \\
\hline \multirow{2}{*}{ VC60 $\gamma о-$} & Dur & 35 & 315 & 315 & 325 & 260 & 350 & 230 & 225 & 210 & 210 & 210 & 210 & 200 & 200 & 200 & 200 & 195 & 195 \\
\hline & Desv & 3,5 & 17,7 & 17,7 & 10,6 & 3,5 & 3,5 & 3,5 & 3,5 & 7,1 & 3,5 & 0,0 & 0,0 & 3,5 & 3,5 & 3,5 & 3,5 & 3,5 & 1,4 \\
\hline \multirow{2}{*}{ VC90 $\gamma_{0+}$} & Dure & 330 & 350 & 330 & 320 & 260 & 250 & 230 & 220 & 205 & 205 & 205 & 205 & 195 & 195 & 195 & 195 & 190 & 190 \\
\hline & Desvio-padrão & 17,7 & 35,4 & 7,1 & 46 & 42,4 & 28,3 & 10,6 & 7,1 & 14,1 & 10,6 & 8,5 & 7,1 & 5,7 & 3,5 & 1,7 & 7,1 & 8,5 & 10,6 \\
\hline Variável & Distância $(\mu \mathrm{m})$ & 475 & 500 & 525 & 550 & 575 & 600 & 625 & 650 & 675 & 700 & 725 & 750 & 775 & 800 & 900 & 1000 & 1500 & 2000 \\
\hline \multirow{2}{*}{ VC60 $\gamma 0^{+}$} & Durez & 200 & 200 & 200 & 195 & 195 & 195 & 195 & 195 & 195 & 195 & 200 & 200 & 210 & 205 & 195 & 195 & 200 & 180 \\
\hline & Desvio- & 0,0 & 0,0 & 0,0 & 0,0 & 0,0 & 0,0 & 3,5 & 7,1 & 14,1 & 14,1 & 14,1 & 14,1 & 14,1 & 17,7 & 7,1 & 3,5 & 7,1 & 10,6 \\
\hline \multirow{2}{*}{ VC60 $\gamma 0-$} & Dureza & 195 & 195 & 195 & 195 & 185 & 185 & 185 & 185 & 180 & 180 & 180 & 180 & 180 & 190 & 190 & 200 & 190 & 190 \\
\hline & Desvio-padrão & 3,5 & 4,9 & 4,9 & 4,9 & 4,9 & 4,9 & 4,9 & 4,9 & 4,9 & 4,9 & 4,9 & 4,9 & 4,9 & 4,9 & 0,0 & 3,5 & 3,5 & 3,5 \\
\hline \multirow{2}{*}{ VC90 $\gamma \mathrm{O}^{+}$} & Dureza média & 185 & 185 & 185 & 185 & 185 & 185 & 185 & 185 & 185 & 185 & 185 & 185 & 195 & 195 & 200 & 195 & 190 & 190 \\
\hline & Desvio-padrão & 10,6 & 10,6 & 10,6 & 10,6 & 10,6 & 10,6 & 10,6 & 10,6 & 10,6 & 10,6 & 5,7 & 0,0 & 2,1 & 2,1 & 7,1 & 3,5 & 14,1 & 0,0 \\
\hline
\end{tabular}


Márcio Tadeu Gravalos et al.

Tabela 4 - Valores médio e desvio-padrão obtidos no ensaio de tração.

\begin{tabular}{c|c|c|c|c|c|c}
\hline Variáveis & LR (MPa) & Desvio-padrão & LE (MPa) & Desvio-padrão & Al (\%) & Desvio-padrão \\
\hline Norma (mínimo) & 550 & & 260 & & 35 & \\
\hline VC60 $\gamma \mathbf{0}^{+}$ & 588 & 15 & 318 & 4 & 31 & 2 \\
\hline VC60 o- $^{-}$ & 559 & 9 & 323 & 4 & 27 & 2 \\
\hline Vc90 $\gamma \mathbf{0}^{+}$ & 581 & 13 & 308 & 6 & 35 & 1 \\
\hline
\end{tabular}

lado, observa-se, na Figura 4, que os perfis de dureza obtidos na camada encruada foram bastante semelhantes, indicando que os ângulos de saídas, negativo ou positivo, não contribuíram para minimizar a formação da superfície encruada.

\subsubsection{Aresta de saída}

A Figura 7 apresenta a face da aresta de saída das ferramentas utilizadas na usinagem. As regiões mais claras da Figura 7 mostram a presença de partículas do aço aderidas na aresta de saída da ferramenta. A análise dessas áreas claras (Figura 8) identificou a presença de elementos químicos como cromo, níquel, molibdênio e silício, que fazem parte da composição do aço inoxidável superaustenítico, mas que não fazem parte da ferramenta de metal duro, que contém, como elemento principal, o carboneto de tungstênio (WC), com triplo revestimento composto de $\mathrm{Ti}(\mathrm{C}, \mathrm{N})+\mathrm{Al}_{2} \mathrm{O}_{3}+\mathrm{TiN}$, con-

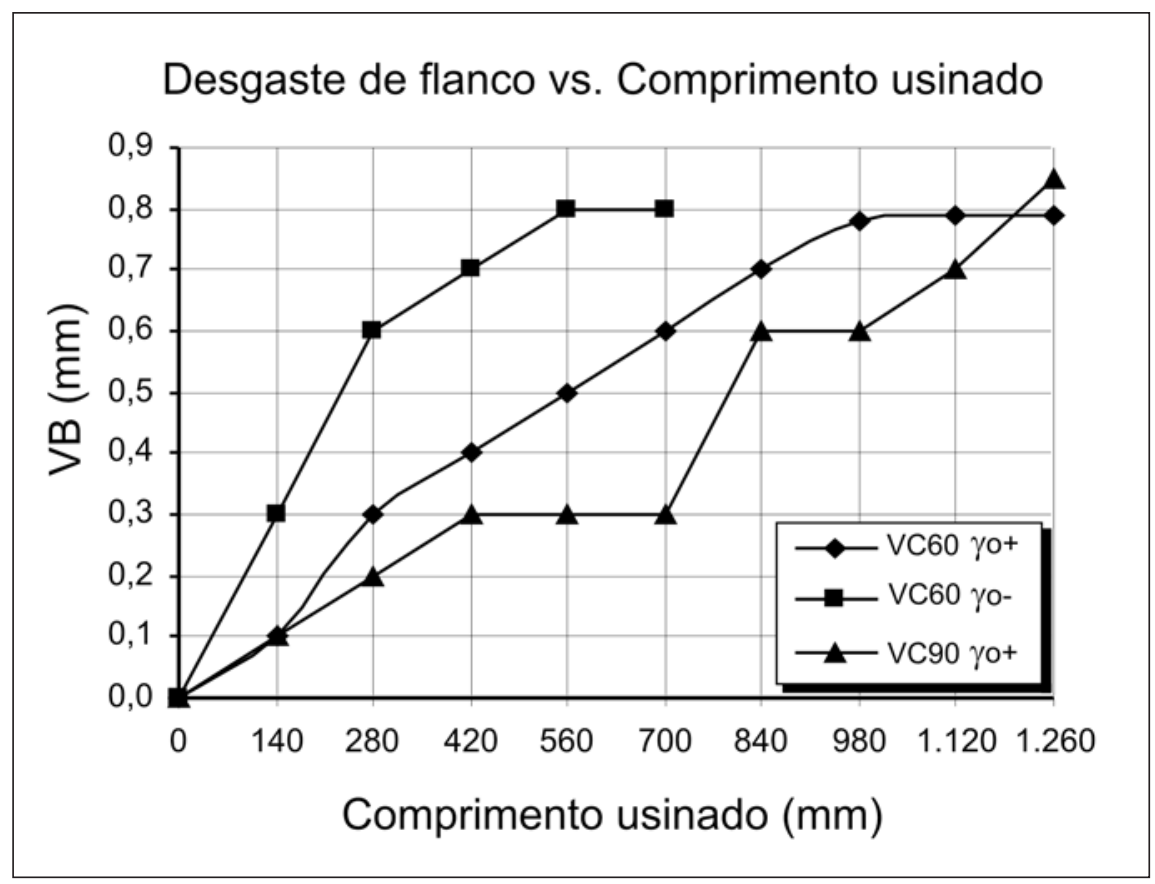

Figura 5 - Desgaste das três ferramentas utilizadas na usinagem.

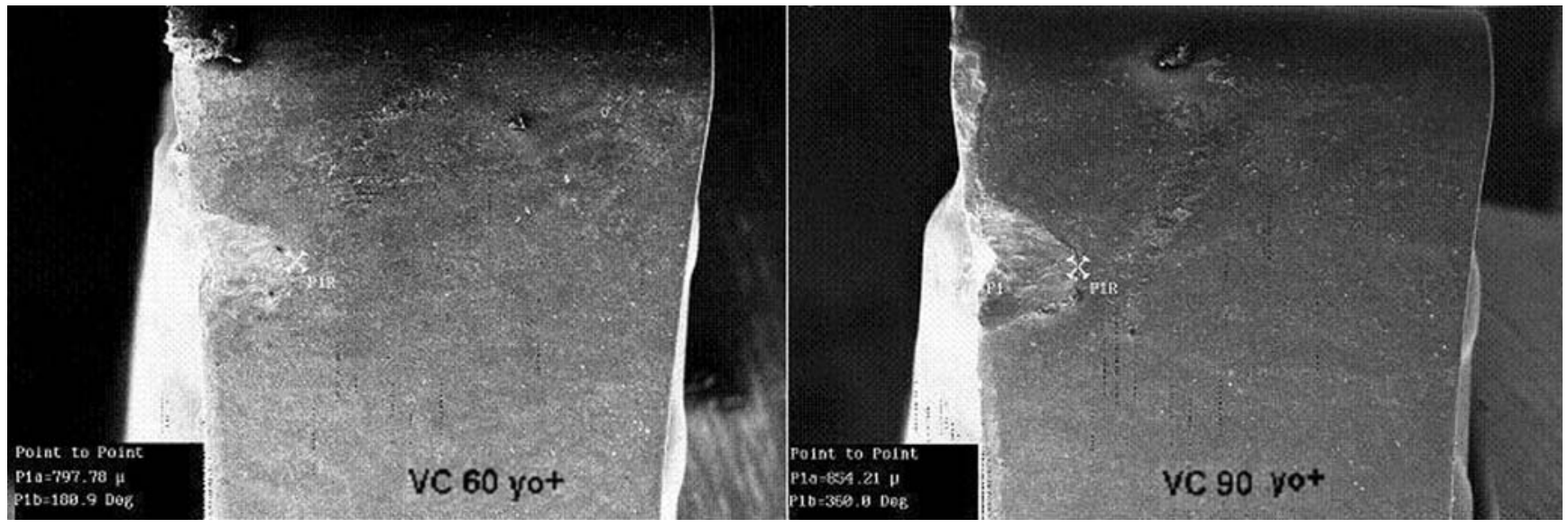

Figura 6 - Desgaste de flanco nas ferramentas com ângulo de saída positivo. 


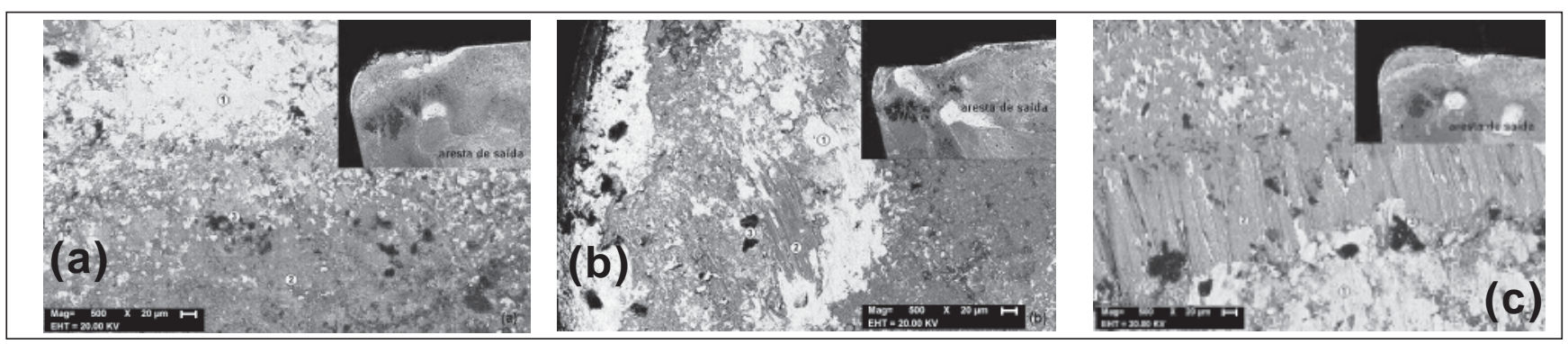

Figura 7 - Secção da superfície de saída com difusão das partículas do aço superaustenítico (MEV). (a) VC = 60 m/min e ângulo de saída positivo. (b) $\mathrm{VC}=60 \mathrm{~m} / \mathrm{min}$ e ângulo de saída negativo. (c) $\mathrm{VC}=90 \mathrm{~m} / \mathrm{min}$ e ângulo de saída positivo.

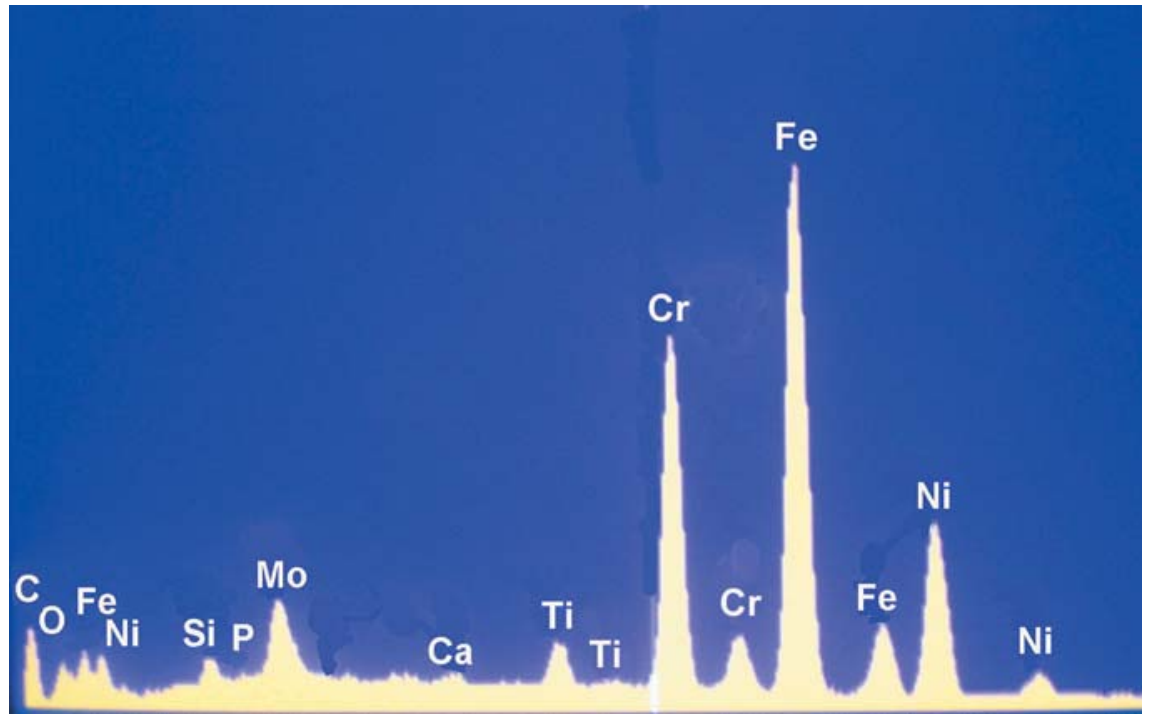

Figura 8 - Análise qualitativa dos elementos na superfície de saída (MEV-EDS).

firmando a adesão de partículas do aço na aresta de saída da ferramenta. A aderência de partículas do material usinado na superfície de saída da ferramenta corresponde ao desgaste por difusão que ocorre durante a usinagem em elevadas temperaturas em materiais com baixas propriedades térmicas [12].

\section{Conclusões}

Para um aço inoxidável superaustenítico ASTM A351 CN3MN, usinado com velocidade de corte (Vc) de 60 ou $90 \mathrm{~m} / \mathrm{min}$, utilizando-se pastilhas de metal duro, padrão ISO CNMG 120412, com tripla cobertura [ $\mathrm{Ti}(\mathrm{C}, \mathrm{N})+\mathrm{Al}_{2} \mathrm{O}_{3}+\mathrm{TiN}$ ] e ângulos de saída do conjunto (portaferramenta e inserto) de $+4^{\circ} \mathrm{e}-3^{\circ}$, conclui-se que:

1. A usinagem provocou o encruamento do aço, elevando sua dureza superficial de 200 para 350 HV. A região encruada atingiu uma profundidade de até $350 \mu \mathrm{m}$, a partir da superfície usinada.

2. A presença das partículas do aço inoxidável superaustenítico aderidas na superfície de saída da ferramenta de corte indica que o corte ocorreu em altas temperaturas.

3. Os diferentes ângulos de saída das ferramentas utilizadas, um positivo e outro negativo, provocaram igual elevação na dureza superficial. Por outro lado, os valores de desgastes de flanco, medidos ao longo da usinagem, indicaram que o ângulo de saída positivo contribui para o aumento da vida útil da ferramenta.

\section{Referências bibliográficas}

[01] ASTM A 351/351M-03. Standard specification for casting, austenitic, austenitic-ferritic (duplex), for PressureContaining Parts, p.137-141, 2004.

[02] BLAZINSKY, T.Z. Materials at high strains rate. Elsevier Science Magazine, Amsterdam, 1992.

[03] LACK, E., BOHMANN, A., SCHARF, M., WERNER, E. Adv. Eng. Materials, $2^{\text {a }}$ ed., p.750-752, 2000.

[04] DINIZ, A.E., MARCONDES, F.C., COPPINI, N.L. Tecnologia da usinagem dos metais. $4^{\mathrm{a}}$ ed. São Paulo: Editora Artliber, 2003.

[05] JIANG, L., ROOS, A., LIU, P. The influence of austenite grain size and its distribution on chip deformation and tool life during machining of AISI 304L. Journal of Metallurgical and Materials Transactions A, v.28A, n. 11, p.2415, 1997.

[06] NASH, W.A. Resistência dos materiais, $2^{\mathrm{a}}$ ed. São Paulo: Ed. McGraw-Hill, 1982.

[07] NICKEL DEVELOPMENT INSTITUTE. Machining Nickel Alloys, 1998.

[08] OUTUKUMPU, Steel Stainless Properties-Work-Hardening, p.5763, 2005.

[09] ROSE, S. Work hardening-a material kind of problem. Tooling and Production Magazine, Ohio, 1999.

[10] SAOUBI, R.M, CHANDRASEKARAN, H. Role of phase and grain size on chip formation and material work hardening during machining of single and dual phase steels, Journal Ironmaking and Steelmaking of Institute of Materials, Minerals and Mining, v.37, n. 3, p.258-264,2004.

[11] SHAW, M.C. Metal cutting principles. $2^{\mathrm{a}}$ ed. New York: Oxford University Press, 2005.

[12] TRENT, E.M.; WRIGHT, P. K. Metal Cutting. $2^{\mathrm{a}}$ ed. Woburn, USA: Butterworth-Heinemann, 2000.

\section{Artigo recebido em 30/07/2006 e} aprovado em 05/10/2006. 